\title{
An Inquiry and BLended Learning Module for Senior EngineERING Design
}

\author{
M. Eggermont, T. Freiheit, R. Brennan \\ Schulich School of Engineering, University of Calgary \\ Email:meggermo@ucalgary.ca|tfreihei@enme.ucalgary.ca|rbrennan@ucalgary.ca
}

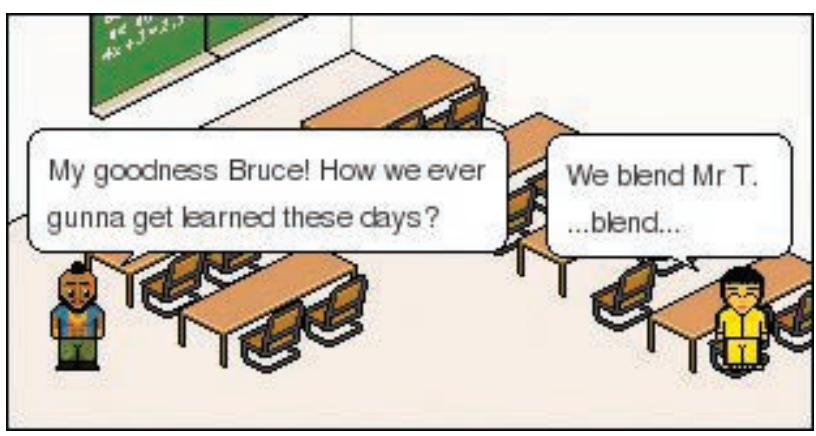

Figure 1. Blended Learning (from [1]).

\begin{abstract}
University of Calgary delivers a full-year "Mechanical and Manufacturing Engineering Design Methodology and Application" course where students gain basic design methodology knowledge and associated skills through lectures and tutorials. The primary "vehicle" used for student experiential learning is a team-based, openended design project. The problem often encountered is that students fail to see "the forest for the trees". More specifically, they often fail to see how the design process applies to their project and potentially miss the main message of the course. This paper proposes a short inquiry-
\end{abstract}

based learning exercise, augmented with web-based teaching modules, to more effectively prepare students for the "application" aspect of the course. Student teams will experience the full design methodology through a compressed "mini-project" at the beginning of the term, before they have any preconceived notions about the design process. Mind-mapping has been identified as the e-learning tool to organize this mini-project. A pilot project testing the use of mind-maps was conducted in a first year design course, exploring issues related to its implementation. 


\section{INTRODUCTION}

Like other Canadian capstone design courses, the full-year Mechanical and Manufacturing Engineering Design Methodology and Application course at the University of Calgary is intended to provide students with an opportunity to learn design methodology and associated skills. In this course, students gain basic knowledge and concepts through lectures and tutorials on a variety of subjects important to the design process. The primary "vehicle" used for student learning at the heart of the course are team projects, where students gain experiential learning via a team-based, open-ended design project.

As implied by its title, this course focuses on both design methodology and design application. The first aspect of the course, design methodology, involves gaining an understanding of the Product Development Process (PDP), the fundamentals of project management, and aspects of design theory (e.g., design for manufacture, design for the environment, robust design). Currently, this material is taught in the standard format of lectures and tutorials and is assessed using written tests.

The second and larger aspect of the course, design application, involves the application of design methodology to a team-based, open-ended design project. For example, projects from 2004/2005 include the design of a minefield mattress, a solarpowered bike, a material handling system, and a ski binding testing apparatus. Assessment of this aspect of the course is primarily through reports and design reviews (i.e., meetings between the student team, their sponsors, and their advisors) that are strategically placed throughout the academic year to correspond with each phase of the design process.

The problem that we have encountered is that students often enter the course with the expectation that it is about "doing a project" or become so deeply involved in their projects that they fail to see "the forest for the trees". More specifically, they often fail to see how the design process applies to the solution of general design problem, and specifically their project, and potentially miss the main message of the course.

As a result, the key issue addressed in this paper is how to more effectively enable students to put theory into practice and use the course methodology when moving on to the "application" aspect of the course. In particular, it is important that students are provided with a more meaningful presentation of the design process before they embark on their major project than they would obtain from lectures and tutorials alone.

To address this issue, we are developing a short inquiry-based learning exercise, or "mini-project" that will be augmented by web-based teaching modules, that will provide student teams with a very compressed version of an open-ended design project at the beginning of the term before they have any preconceived notions about the design process. In this paper we focus on the development of this inquirybased, blended learning exercise, and summarize our experience with e-learning tools in a trial project with the Schulich School of Engineering's first-year Design and Communication class.

The paper begins with some background on the Mechanical and Manufacturing Engineering Design Methodology and Application capstone design course and its relationship to the proposed mini-project. This mini-project is meant to act as a bridge between the course methodology and application component. In Section 3, we describe our current class plan for the mini-project and identify the areas where e-learning tools appear to be most appropriate to support student and instructor activities. These e-learning tools will be used in addition to more traditional bridging methods. In Section 4, a number of course methodology and application bridging methods will be discussed, followed by a discussion of mindmapping software, one of the e-learning tools that will be used to support the mini-project. In Section 5 , a pilot project and the lessons learned using mindmapping software conducted in a first year design course will be discussed. The paper concludes with a summary of our plans for the implementation of this blended learning project and our thoughts on the next steps in this project.

\section{The Capstone Design Course}

The fourth year design course in mechanical and manufacturing engineering was developed to be in line with the Canadian Engineering Accreditation Board's main objectives for capstone design: to provide students with a significant design experience based on the knowledge and skills acquired in earlier course work, and give students exposure to the concepts of team work and project management [2]. As noted previously, this is accomplished through conventional lectures and tutorials on engineering design methodology, with the main focus of the 


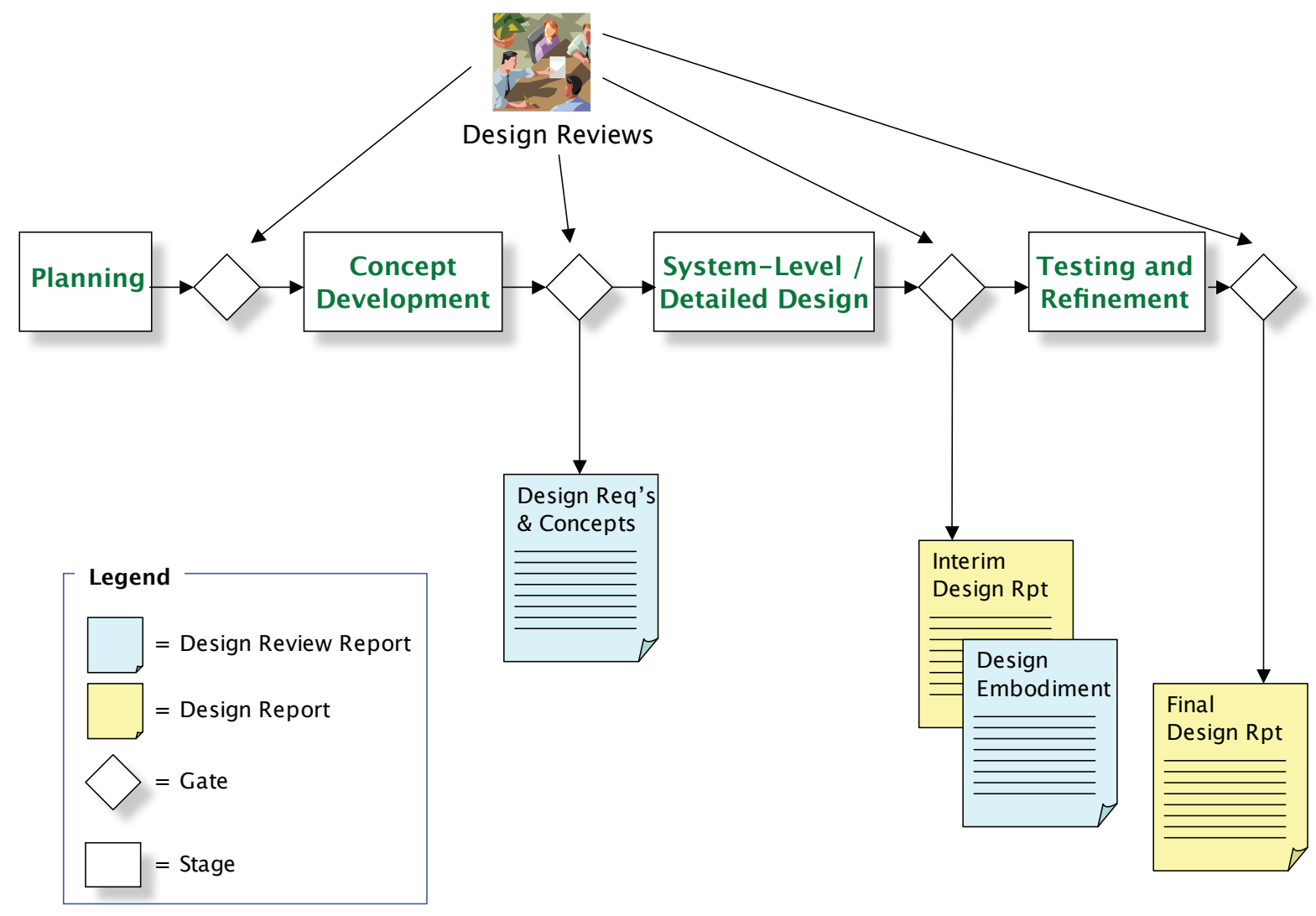

Figure 2. Capstone design course structure.

learning process through full-year, open-ended design projects. These team-based projects are predominantly industry-sponsored, however there is also the opportunity for teams to work on facultysponsored or student-sponsored projects.

Given the nature of the projects in mechanical and manufacturing engineering, the course is structured around a general Product Development Process (PDP) [3] as illustrated in Figure 2. In this course, deadlines associated with deliverables such as design reports and design reviews can be thought of as "gates" between the main stages of the PDP. In other words, student teams are required to use the feedback from their reports and reviews to not only help refine their final design report, but also guide their work in the subsequent stages of the product development process.

Our objective is that the students see the utility of this general methodology for engineering design during the process of their full-year project. However, our experience has been that, at best, this is recognized near the end of the course by the top-performing teams and at worst, it is viewed as a hindrance to team-members (i.e., "hoops" that they must jump through for grades).

The problem is not with the complexity of the PDP, as students appear to understand its basic principles when assessed via written tests. Instead, it appears the problem is with the application of the PDP and two basic misperceptions about design methodology. First, that the student team already has the answer to the design problem, and as a result, wants to cut to the chase rather than get bogged down in process. Second, that the PDP is a linear rather than an iterative process, as a first glance at Figure 2 would imply.

Our experience has shown that in both cases student teams discover the value of the PDP too late in the process. For example, in the first misperception, a whole set of promising solutions may have been discounted because the team rushed through the 


\begin{tabular}{|c|c|c|c|c|}
\hline Week & Day & Lecture & Lab & Deliverable \\
\hline 1 & Wed. & $\begin{array}{l}\text { Introduction to PDP; Introduction to the } \\
\text { Mini Project exercise. }\end{array}$ & $\begin{array}{l}\text { Mindmapping \& FreeMind software } \\
\text { tutorial; Requirements exercise }\end{array}$ & \\
\hline 1 & Thur. & & & $\begin{array}{l}\text { Requirements phase notes (in } \\
\text { FreeMind) due on Blackboard. }\end{array}$ \\
\hline 1 & Fri. & $\begin{array}{l}\text { Requirements critique; Concept } \\
\text { Generation exercise }\end{array}$ & & \\
\hline 2 & Mon. & Concept Selection exercise & & \\
\hline 2 & Tue. & & & $\begin{array}{l}\text { Concept Generation and Concept } \\
\text { selection phases notes (in FreeMind) } \\
\text { due on Blackboard }\end{array}$ \\
\hline 2 & Wed. & $\begin{array}{l}\text { Concept Generation and Concept } \\
\text { Selection critique }\end{array}$ & $\begin{array}{l}\text { Design Embodiment and Prototyping } \\
\text { exercise }\end{array}$ & \\
\hline 2 & Thur. & & & $\begin{array}{l}\text { Design Embodiment phase notes (in } \\
\text { FreeMind) due on Blackboard }\end{array}$ \\
\hline 2 & Fri. & Verification exercise (e.g., competition) & & \\
\hline & Mon. & Mini Project critique and awards & & \\
\hline
\end{tabular}

Figure 3. Mini-project class plan

concept development phase while focused on an idée fixe. In the second misconception, teams may for example find themselves with a prototyping plan that does not serve to verify their product because they did not see the link between customer needs, target specifications, and prototype planning.

Although there remains some consolation to see teams discover the value of the PDP at the end of their project, it is our opinion that the students' learning experience (and course satisfaction) would be higher if they could see this from the start. In the next section we provide an overview of the previously introduced mini-project that is intended to address this issue.

\section{ThE MINI-PROJECT}

Like the full-year project, the mini-project is designed as an inquiry-based learning approach to engineering education that involves the learner in his/her own education in order to acquire skills, critical thinking ability, and sound judgment. Through this approach, students not only gain engineering science and design knowledge, but also learn how to acquire and use it to solve real-life problems similar to their upcoming full-year project.

Unlike the full-year projects that are unique to each student team, a common project is used for the mini-project. For example, a relatively simple project such as the design of an elastic-powered car is given to the entire class (approximately I4O students, 25 teams) to be completed in $\mathrm{I} 1 / 2$ weeks.

Given the large size of our class and the short time frame for the mini-project, management becomes an issue. In order to facilitate this mini-project, a blended-learning approach is being developed that combines traditional classroom and laboratory work with e-learning technology. More specifically, we use a combination of online learning approaches via intraand internet (e.g., interactive web pages, discussion 
forums, file transfer via Blackboard [4]) and specific software tools (e.g., the mind- mapping [5] software FreeMind [6]).

Students work on the mini-projects in the same team as they will be in for the full-year project over the course of I $1 / 2$ weeks during lecture and laboratory periods. A sample class plan is shown in Figure 3.

As can be seen in this figure, the lecture and laboratory periods are used primarily for handson student work (i.e., "exercises") on each phase of the project and presentations to their peers (i.e. "critiques"). All mini-project deliverables are in electronic form.

In order to manage the size of the class, and to keep everyone engaged, our plan is to randomly select teams for the project critiques based on the material submitted electronically. The idea here is to allow individual teams to use their electronic submission to briefly summarize their progress at key stages of the project and field questions from their peers. These critiques will also provide the instructor team the opportunity to comment on the teams' decisions in the context of the PDP.

We feel that by supplementing the in-class work shown in Figure 3 with e-learning technology, students will not only be provided with the requirements of the mini-project exercise online, but will also be invited to publish and share their own content about this inquiry topic. In this case, student teams will share their views on the design process. For example, they may be asked to discuss the following:

I. What types of activities undertaken during the development of your car and what was the approximate percentage of time devoted to each activity?

2. How would you change the design process with a view to improving your car's performance?

3. What are the best aspects of working on a team?

4. What are the worst aspects of working on a team?

The idea is to facilitate, in person (i.e., during class time) and online, discussions on design process issues that will serve as material for future lectures on design methodology. For example, the "activities" discussed in the first question should lead nicely into the activities involved in each phase of the design process, while discussion on the third and fourth questions should help teams identify their limitations. Additionally, it is hoped that this material will be more relevant to the students since is came from their own experiences.
Before discussing the e-learning technologies selected to facilitate the mini-project, a brief summary of current methods of linking or bridging design theory with design application will be discussed.

\section{BRIDGING METHODS}

During the lectures, product development processes, project management and design theory are addressed. The challenge to the students is to apply lessons learned to their team-based open-ended design project. Current methods typically used to monitor student research into design requirements, concept generation, detailing and verification stages of the design process are the use of logbooks, instructions sheets and case studies. This section will discuss the pros and cons of these four "bridging" methods. In our case, bridging refers to the process of connecting the methodology of design in the shape of lectures and tutorials to the actual application of design.

One method of keeping track of the design process is the student logbook. The advantage to the logbook is that it is portable and spontaneous. Largely a free format - students do have to date pages, add signatures when needed, and cross out blank spaces when pages are unused - students can take minutes, do calculations and sketch and discuss design ideas.

The fact that the logbook is an individual document is a pro and a con, in the sense that it does show an individual's contribution to the group but does not show the groups' progress as a whole. The disadvantage to the logbook is that it has less structure and can be random and unorganized. It is also a linear format which does not always allow for connections to be made to previous ideas or observations.

In addition to requiring a logbook, an instructor might make use of "project requirements" sheets as additional bridging method. Project requirements documents (and also the corresponding rubrics) spell out what is required from the students for written reports, design reviews, etc. The sheets control the outcome, ease student stress (since they have a good idea of what the instructor wants), and provide schedules; as well, they arguably may limit student creativity, can overly direct students, and are viewed, especially by students, as being rigid. Project requirement sheets are a balancing act; specific requirements help with assessment and provide structure for the students (which is typically appreciated by engineers) at the possible expense of creativity (which is sought after for designers). 


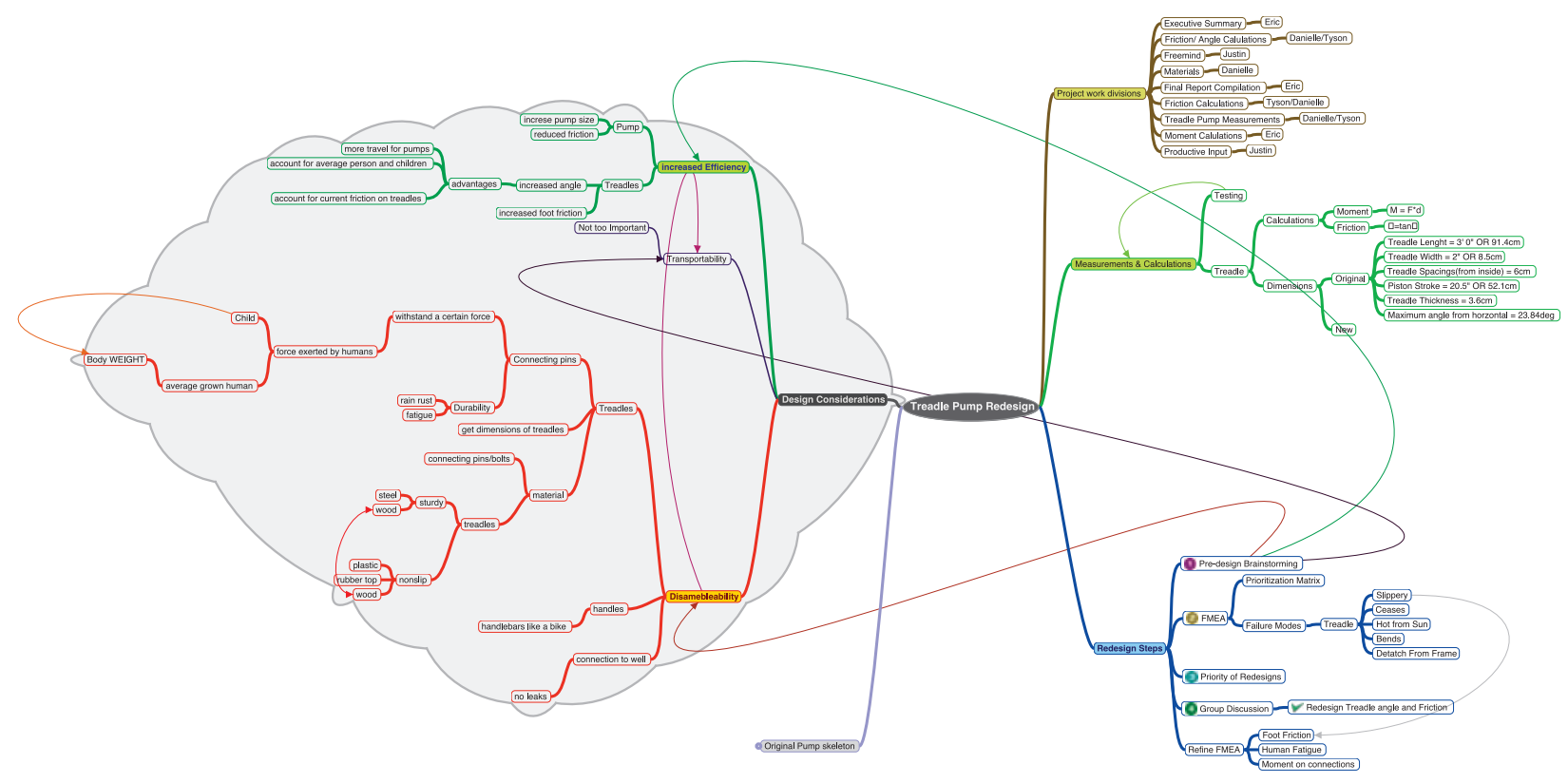

Figure 4. Sample mindmap.

Another bridging method is the use of case studies which show students previous processes that may mirror or trigger ideas for their future design attempts. The advantage of case studies is that they are "real" and allow students to learn by example, much like the court system's use of precedents. While case study will have the content the instructor is trying to get across, this content may be too difficult to see. The content may also be too limited to show the overall process because it is too specific. In order to be a manageable learning tool, a case study also tends to be smaller than a realistic design, i.e., the type of design the students encounter later in the course and even later in practice.

A final bridging method is the use of concept maps to map the cognitive progress of a design. One form of a concept map is the mind-map, which associates concepts by linking them together in a tree structure. The advantage to the instructor is that he/she can show a general, non-specific project map. This map can be detailed for specific projects, triggering the appropriate questions at the appropriate stages.

FreeMind was selected as the e-learning software to help students perform a mind-map, and is, as the name suggests, a free download compatible with Linux, Mac OSX, and MS Windows (this was a requirement for the software). FreeMind proved to be flexible, intuitive, easy to use, and allowed concepts to be easily linked together in a graphical format. It is "a good way to organize information because it helps students to pull together information already known about a subject and to comprehend new information as they learn" [12]. It is also image-oriented and allows easy creation of pdf's, webpages and linked outlines. It forces organizational thinking, yet still allows for changes on-the-fly.

A test design project using this software was conducted in a first year design course. The next section discusses the findings from this pilot project.

\section{EXPERIENCE WITH A SHORT INQUIRY-BASED Pilot Design Exercise}

A pilot project was conducted in a first year design course using FreeMind mind-mapping software [Fig. 4]. Of interest was whether the use of mind-maps would result in a more thorough approach to a design problem. Buzan [5], describes a mind-map as "a graphic technique, which harnesses the full range of cortical skills - word, image, number, logic, rhythm, colour and spatial awareness". The pilot project is intended to gain insight into if students using mindmaps in a design project would:

I. See the forest for the trees.

2. Create a simulation of a "team" logbook. 


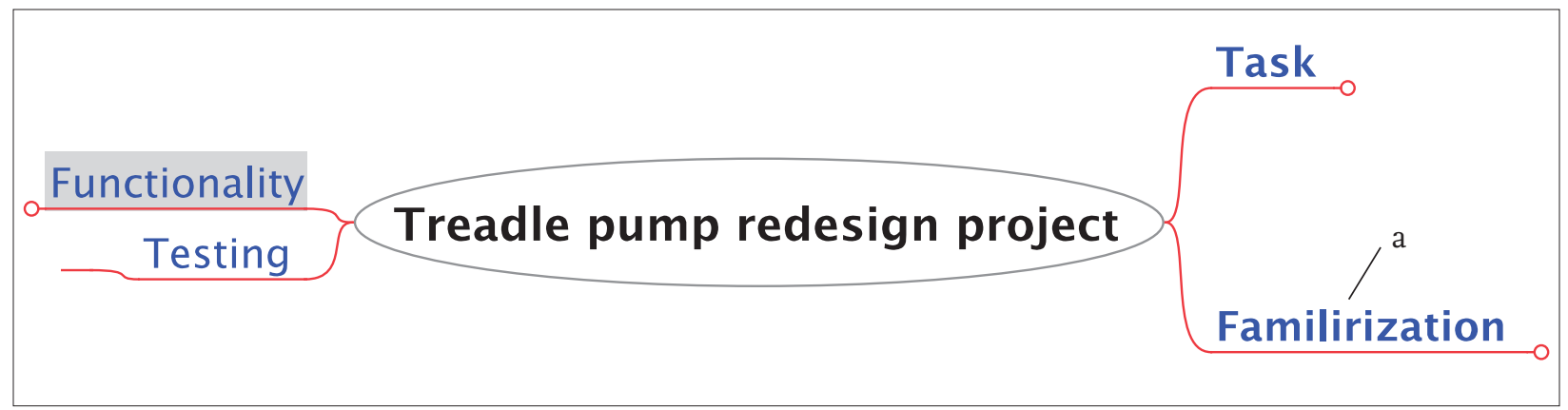

Figure 5a. Stage-one student mindmap.

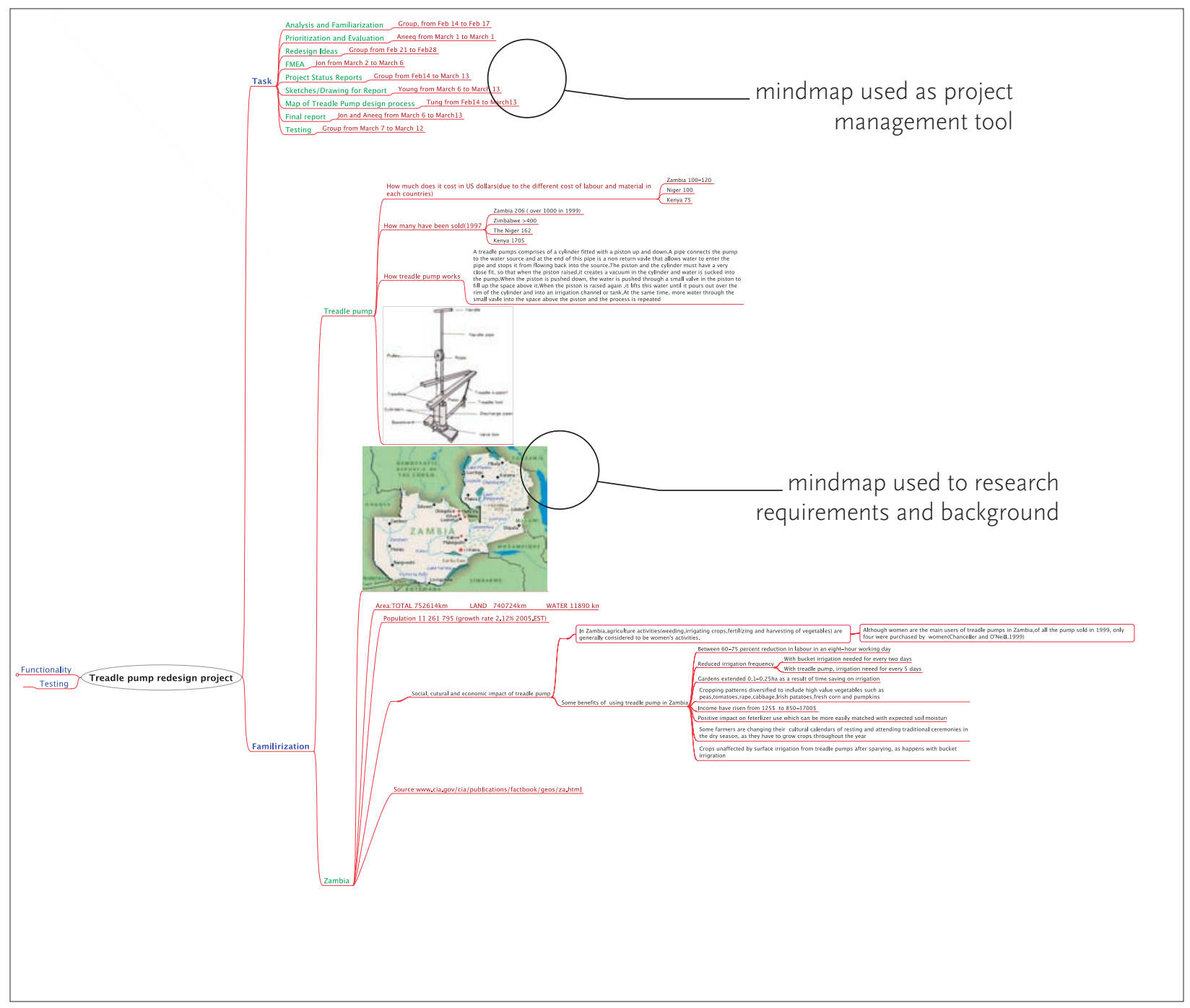

Figure 5b. Stage-two student mindmap. 


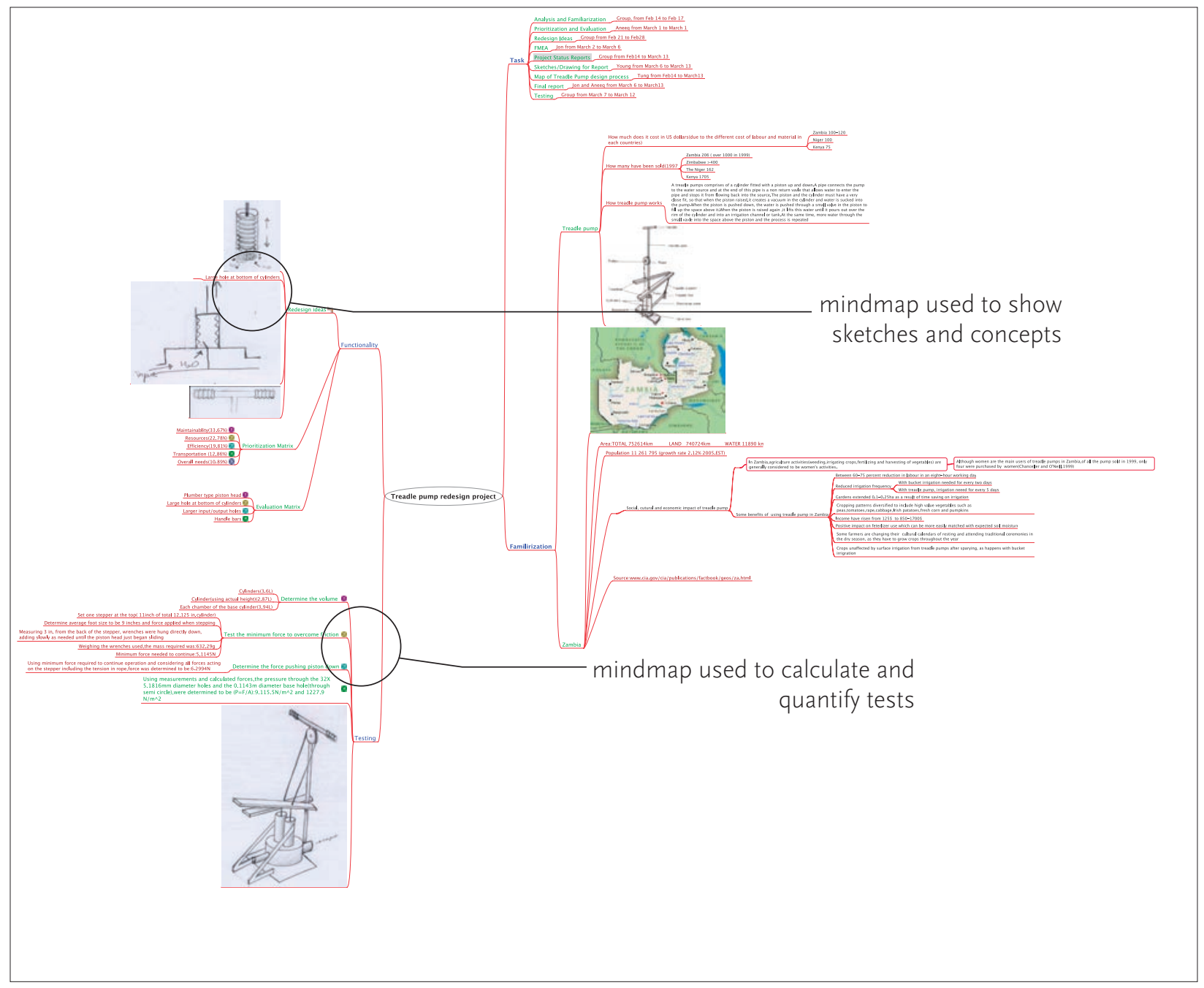

Figure 5c. Stage-three student mindmap.

3. Make easy connections between design stages.

In addition, the pilot project is intended to test if mind-maps will allow instructors to see when a design project may have gone off-track.

In the winter term of $2005 / 06$, all 550 first year engineering design students were introduced to FreeMind. The software tool was used for a three-week redesign project that was part of a yearlong project with Engineers Without Borders (EWB). Students were asked to redesign the existing, somewhat mature technology of a treadle pump. Students were given some requirements up front, one of which was that women and children should be able to operate the treadle pump. The project was largely focused on design management, part of which was to create a Gantt chart.
Students had to create three mind-maps using FreeMind [Fig. 5a-c], capturing the status of their redesign at the end of each week. Figure 5a shows four areas students identified as important design categories. Figures 5b-c are representative of the evolution of their mind-maps during subsequent weeks. In figure 5b students have started to look at requirements and at the geographical location in which the treadle pump has to be used. In the final figure [5c], we see the entire design picture complete with concept sketches and quantified data. The software allowed, as previously mentioned, the easy creation of an outline, which some groups used to structure their final reports [Fig. 6a-d].

We observed that by using the non-linear mindmap format students were able to see how some 


\section{Treadle Pump}

目

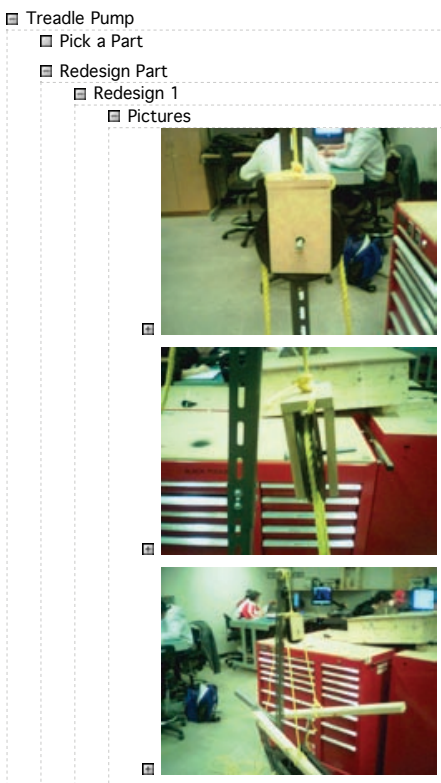

曰 Pulley Holder

Allows rotation of the pulley

曰 Design Studies Prototype

$\square$ Test Results

$\square$ - functioned properly on device - pulley lined up exactly with

treadle ropes - difficulty fitting shaft into holder

$\square$ Angle of Tilt

$20^{\circ}$

$\square$ Improvements

$\square$ - Get a pulley that would fit the pin - Make out of metal -

Reinforce area where pin attaches to pulley holder

口 Solutions

$\square$ - use high stength rope capable of lifting about 200lbs periodically check rope for fraying and replace if necessary

Redesign 2 $\square$ Design Studies

$\square$ Changes

$\square$ - Fixed size of axel - Used proper sized bolts

$\square$ Testing

$\square$-Works properly - No problems

$\square$ Concerns

日 - Lifetime of Rope

$\square$ Solutions

$\square$ - use high stength rope capable of lifting about 200lbs - periodically check rope for fraying and replace if necessary

$\square$ Pulley

日 Analysis

曰 Cultural Impac

日 Social

$\square$ Social and Cultural Impact
E Drawings
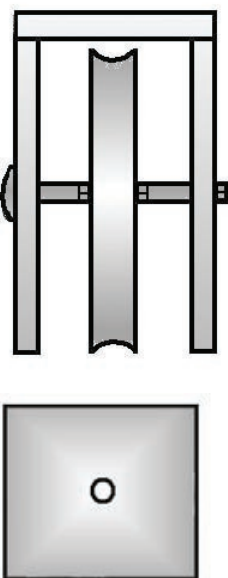

田

曰 Design Studies

I FMEA

$\square$ Define subsystems

日 Rope \#

$\square$ Connects pulley to pedals

日 Rope \#2

$\square$ Connects pulley to frame

曰 Pulley

Allows free movement of Rope \#1
- irrigation, weeding, fertilizing, and harvesting considered women's work - women operate pumps without religious or traditional restrictions

$\square$ Social Benefits

$\square$ - reduced labour demand - reduced irrigation frequency - reduced workload

\section{日 Economic}

$\square$ Economic Impact

$\square$ - increase in household income (rose from $\$ 125$ to $\$ 850-1700$ ) increase in crops grown

$\square$ Benefits

$\square-60-75 \%$ reduction in labour - diversified cropping patterns income from irrigated crops/seeds - better fertilizer use -

unaffected by surface irrigation

$\square$ Cons

$\square$ - increased yield creates market glut - rural transport expensive and unreliable

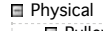

$\square$ Dimensions

- diameter: $14.0 \mathrm{~cm}$ - width (total): $4.0 \mathrm{~cm}$

$\square$ Problems

$\square$ - doesn't line up - cayse fraying, jumping off - increases friction and user effort

Data

口 Can hold about 200lbs

日 Progress Reports

G February 28

E Febru

团 March 8

Figure 6(a-d). Mindmap as XHTML linear outline. 


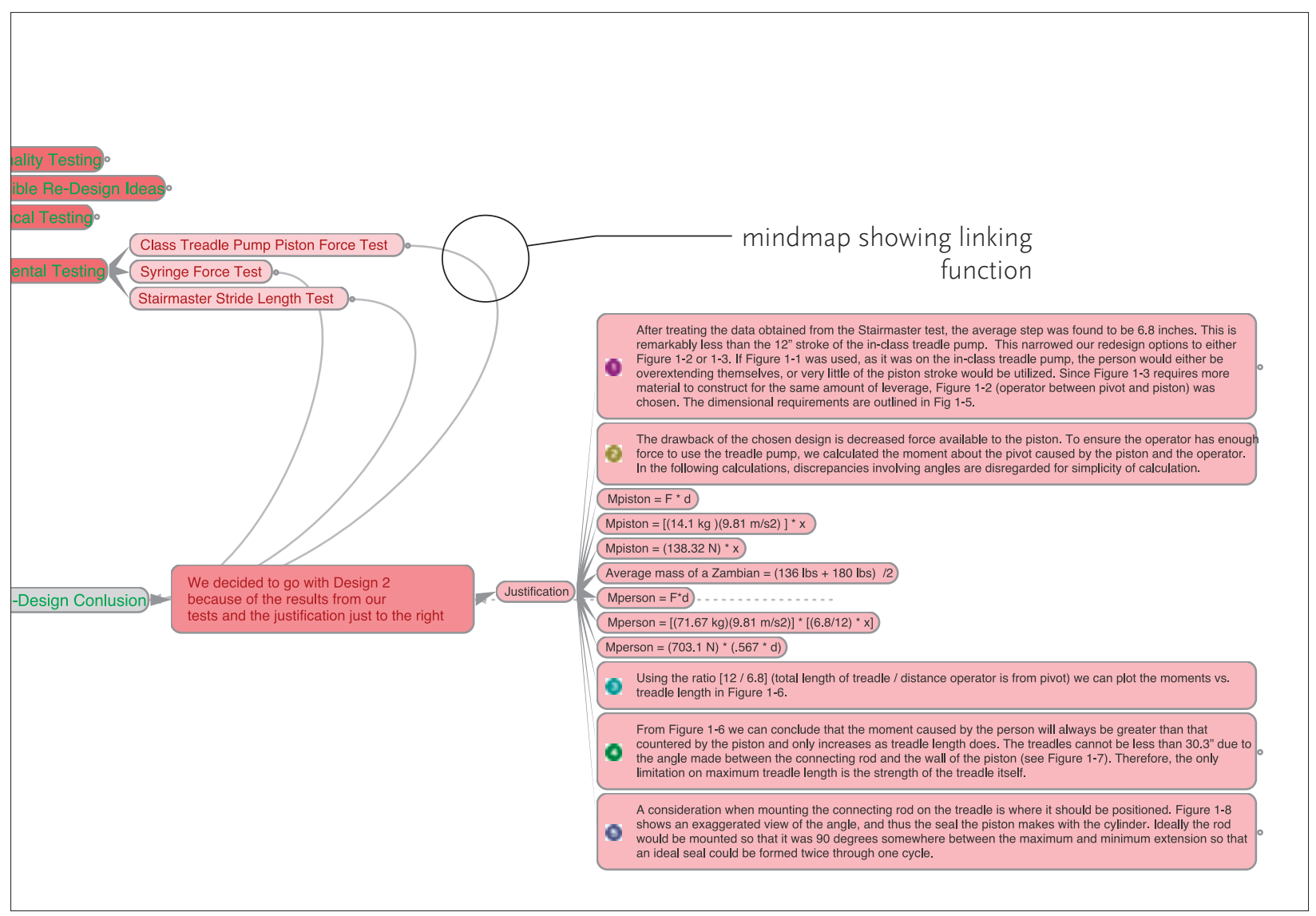

Figure 7. Linking function.

design ideas did not meet the requirements, and that some concepts had to be revisited after the detailing and verification stages of the design process [Fig. 7]. When used, this revisiting/linking software function was one of the approaches that resulted in good mindmaps. Figure 7 shows a partial map in which students showed that a final design decision was made based on a comparative analysis of three design concepts.

FreeMind was given to the students as a tool to explore. Other than having to show the process of redesign over a three week period, no specific deliverables for content were required for each week. But, in the final analysis of 150 maps created in our pilot study, it was determined that some initial requirements would have been useful to set the students on the right track.

Several areas of interest appeared during our analysis of the maps [Fig. 8]:
- The shape of the map was directly correlated to the quality of the map.

- Vertical-oriented or round maps $(\approx 75 \%)$ tended to be thorough and well-planned.

- Horizontal-oriented maps tended to be of poor quality and not thorough.

Within the vertical maps two common characteristics emerged:

- Repetition as an organizational tool was used by about $50 \%$ of the class.

- The repetition of node- and branch-structure caused a more complete analysis of each engineering theory category.

By repeating questions asked within each node, students were able to check whether they had considered every aspect of the design and whether each aspect had been addressed in the following stages [Fig. 9]. 


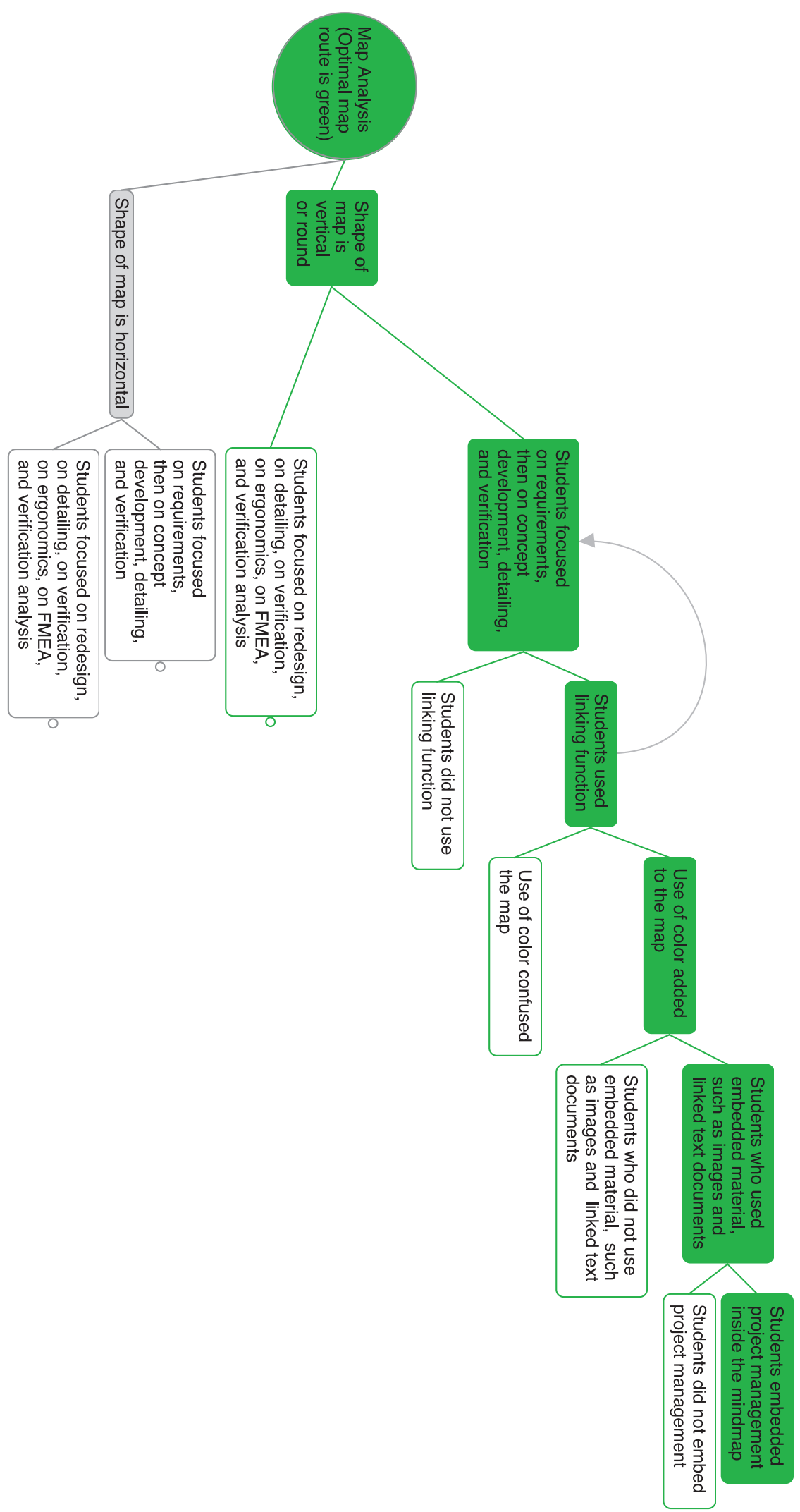


Other characteristics that emerged:

I. Groups that added a separate branch focusing on project management $(\approx 50 \%)$ also tended to show a thorough discussion of their redesign project. This project management branch forced all group members to look at and use the map frequently - very little was forgotten. One of the requirements for future mind-map projects should be a project management component, embedded within the map.

2. A function that no logbook or case study has, is the linking function. Students can visually show in the map where they have gone back to do more research or where they came to certain conclusions that were crucial to their final design [Fig. 7]. About $45 \%$ of groups used this linking function, all of these groups had maps that had a vertical or round shape, perhaps because of the linking arrows, but this linking showed a thoroughness and in general a more rigorously developed map.

3. Another aspect that was looked at was the size of sections branching out from the central "problem statement" node. A significant number of groups $(\approx 38 \%)$ did a very good requirements / familiarization branch. These groups did well in terms of redesign and concept generation because they had a thorough understanding of the problem and were able to link back to requirements frequently. Well developed requirements / familiarization branches resulted in larger subsequent branches and a generally better design outcome. An additional $4 \%$ of groups focused largely on ergonomics, a requirement specifically mentioned by EWB. The pump had to be able to be used by women and children.

In contrast, $38 \%$ of groups focused on the redesign aspect of the project, and on detailing and functionality. Even though these groups made maps, they still got lost in the forest because they jumped to one design idea and never let it go. This group would have been helped by a set of requirements before beginning the mind-map.

4. Little use was made of embedded images and linked text or spreadsheet documents: only about $20 \%$ of groups made use of these functions [Fig. 9]. The mind-map is first and foremost a visual document, meant to give an instant overview of the design process. Images direct the eyes much faster than text and are therefore a good map design element. The embedded text files make for a very thorough map and a generally better supported document. The inclusion of images and text files also resulted in a very rich XHTML document for possible website use. This area will be stressed in the requirements for the mini-project.

5. A final observation was the depth of the maps. Groups that used four or more subcategories in each branch ended up with a very detailed design [Fig. 9].

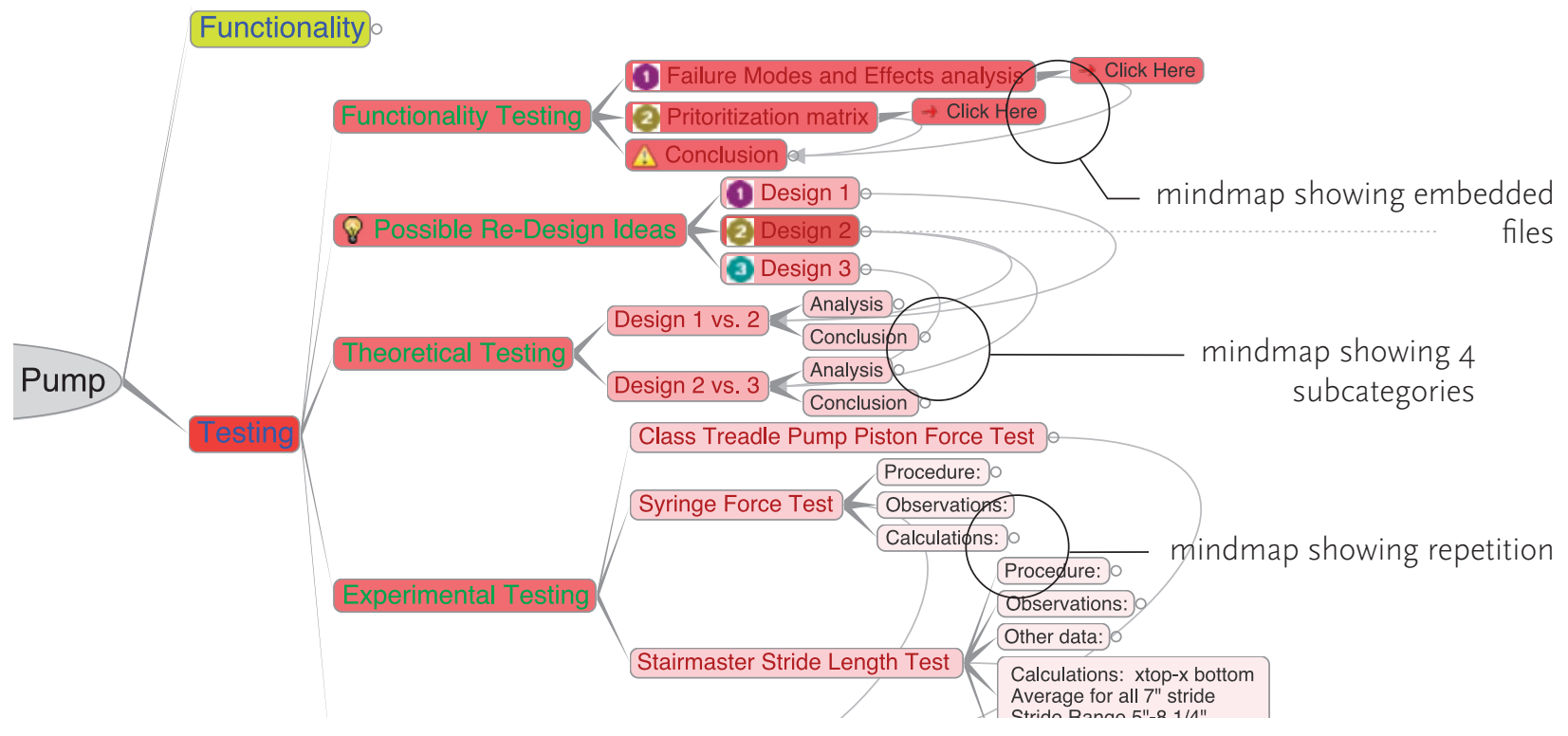

Figure 9. Embedded files and repetition. 
The mind-maps in this pilot project provided the students with a new group work / group management tool. In addition, the maps were useful in generating project status reports and final report outlines. The maps organized research material easily and quickly [6]. With some direction from the instructors, this mind-mapping software will be a good additional "bridging" tool for the upcoming mini-project.

\section{Conclusions and Future Work}

Mind-maps or concept maps have proven to be valuable learning tools. In a recent study the following advantages were found when using mindmap / concept-map strategies [I2]:

- focuses the learning task,

- links learning and new learning,

- visual map of the connections the learner makes between concepts,

- identifies valid and invalid connections made by the student,

- provides a schematic summary of learning,

- leads to deep learning,

- organizes information,

- learning becomes transparent,

- students can self-assess,

- concept maps are individualized and hard to plagiarize,

- assessment becomes part of learning,

- can be assessed within the existing assessment system.

From the pilot project, we were able to answer the four questions set at the beginning of Section 5 . Students began this project with minimal instruction. Our analysis of their work indicates that a significant number of students were able to see the "forest for the trees", with $38 \%$ having detailed maps. Approximately $50 \%$ of teams included a project management branch in their map, showing that many teams were also using the map as a team logbook. Also, mindmaps were partially successful in providing better connectivity between design stages - approximately $45 \%$ of the teams made use of the linking function. Finally, the mindmaps clearly demonstrated that $38 \%$ of teams went off track by only exploring one design solution. Overall, our pilot study successfully demonstrated mindmapping capabilities.

The mini-project will make use of mind-mapping software in order to help students make connections between the theory and practical application of the course. Students will be given certain map requirements in advance, but will be asked to develop "branches" during each stage of the design process. Our analysis of the pilot project indicates these requirements should include:

- A thorough requirements/ familiarization branch, promoting development of a correctly "shaped" map.

- A project management branch forcing all members of the team to add to the "group logbook".

- A "linking back" requirement during the concept generation stage of the map - how and where do your concepts fulfil the requirements.

- The inclusion of images (no larger than $100 \times 70$ pixels) or links in all phases, to give viewers a visual clue where to find pertinent information.

The mini-project assignment will require students to develop their own initial "requirements" branch. Several of these requirement branches will then be discussed in class, after which general requirements based on the PDP methodology will be released, giving students an opportunity to compare their efforts to the methodology. Students can then complete their version and move on to the concept development branch. This sequence will continue throughout the mini-project. By generating their own map, we believe students will start to see the overall design picture. To determine if students are better seeing "the forest from the trees", at the end of this mini-project, they will be asked to produce a small individual mind-map reviewing their mini-project experience by answering a set of questions from the instructors.

In addition to this mini-project module, students will also be encouraged to explore the various design modules on the Canadian Design Engineering Network (CDEN) e-Design Portal $[7,8]$ as they work through their major project. For example, during the concept development phase of their major projects, eDesign Portal modules such as Ideation \& Concept Design module [9] or the Concept Evaluation module [Io] from the Product Development Process (PDP) topic may prove to be useful. As well, student teams may choose to explore case studies from the e-Design Portal to see how other designers made conceptual design decisions (e.g., [II]).

The mini-project will be presented as an online learning module as part of the CDEN e-Design Portal [7], which was developed in conjunction with the University of Calgary's Learning Commons [8]. In 
particular, since the results of the mini-project will be in an XHTML format that is full compatible with any commercial web browser, examples can be easily compiled into a single web-based module. These examples will be made available in conjunction with the initial mini-project requirements as well as links to the software tools used in the mini-project (i.e., FreeMind and Blackboard). When accessing the module, users will be able to view the mini-project assignment (i.e., the project requirements), and then browse through examples of student projects.

The purpose of this module is twofold. First, it is intended for use by engineering design instructors as a template and a case study for an inquiry-based, blended learning exercise on the product development process. More specifically, instructors may choose to use all or part of the mini-project in their course. For example, they may choose to copy the mini-project, use the mini-project as a template with a different design problem, or merely use the tools for an aspect of their design course (e.g., use the FreeMind tool for concept selection).

Secondly, the module is intended to provide a concise example of the product development process for students. This ties back to our initial requirement of helping students to "see the forest for the trees" during the PDP: the mini-project module will allow students to view a design from start to completion in a single sitting (or a single lecture). However, it also has the potential to accomplish much more. In particular, the module provides students with the opportunity to publish and share their own content about an inquiry topic. In this case, student teams will share their views on the design process via the miniproject module. It is our hope that the result will be more accessible than typical PDP teaching materials since it will be in the voices of fellow students who are doing design.

\section{ACKNOWLEDGMENTS}

The authors wish to thank the students and instructors from the 2006 session ENGG 253 (Design and Communication II) for their input on the use of the FreeMind software tool. This research work has been supported by the University of Calgary's Inquiry and Blended Learning Course Development and Enhancement Project and a Marie Curie Transfer of Knowledge Fellowship of the European Community's 6th Framework Program under the contract MTKD-CT-2005-029755: CzechVMXT. This research was conducted under University of Calgary Ethics Approval file no: CEIoI-3780.

\section{REFERENCES}

[I] Blended Learning, Wiki, http://blendedlearning. wikispaces.com/, accessed May 2006.

[2] Canadian Engineering Accreditation Board, Accreditation Criteria and Procedures, Canadian Council of Professional Engineers, 2004.

[3] Ulrich, K.T. and S.D. Eppinger, Product Design and Development, Third Edition, McGraw Hill Irwin, 2004.

[4] Blackboard, Website, http://www.blackboard.com, 2006.

[5] Buzan, T, B., The Mind Map Book: How to Use Radiant Thinking to Maximize Your Brain's Untapped Potential, Plume, I996.

[6] FreeMind, Open Source Project, http://freemind. sourceforge.net/wiki/index.php/Main_Page, 2006.

[7] Brennan, R.W., “The CDEN e-Design portal," Proceedings of the 2nd CDEN International Conference on Design Education, Innovation, and Practice, Kananaskis, Canada, I8-20 July, 2005.

[8] CDEN e-Design Portal, Website, http://apollo.ucalgary. ca/cden/, 2006.

[9] Gregson, P.H., "Ideation and concept design," CDEN e-Design Portal, http://apollo.ucalgary.ca/cden/, 2006.

[Io]Salustri, F.A., "Concept evaluation," CDEN e-Design Portal, http://apollo.ucalgary.ca/cden/, 2006.

[II] Brennan, R.W., "Flexible cut-off saw," CDEN e-Design Portal, http://apollo.ucalgary.ca/cden/, 2006.

[I2] Williams M (2004) Concept mapping - a strategy for assessment. Nursing Standard. I9, 9, 33-38. 